\title{
DESCOBRIR O PRAZER DE ESCREVER
}

\section{Criação coletiva de alunos de segunda série do ensino fundamental resulta em livro e dinamiza o cotidiano escolar}

O Projeto Vivência pedagógica originou-se de um trabalho realizado com alunos da segunda série do ensino fundamental. No início do ano, durante o planejamento dos conteúdos a serem desenvolvidos nesta série, as atividades que constituiriam o eixo da ação pedagógica foram direcionadas a estudos do meio e à elaboração de outras situações de ensino e aprendizagem, significativas para o grupo-classe.

Os estudos do meio foram planejados para enriquecer o processo ensino-aprendizagem. Procurou-se aproveitar os locais oferecidos pela Universidade de São Paulo, por serem didaticamente planejados para visitação de crianças. Geralmente o percurso era feito a pé, a fim de possibilitar um melhor conhecimento espacial do campus pelas crianças.

Lembrando César Coll ${ }^{1}$, a criança só aprende um conteúdo um conceito, uma explicação de um fenômeno físico, social ou outro qualquer - quando é capaz de atribuir-lhe um significado. Procurou-se trabalhar com conteúdos que tivessem uma lógica interna e, ao apresentá-lo à criança, era fundamental que a mesma tivesse compreensão do porquê estar estudando, observando e/ou escrevendo sobre um certo assunto. Neste sentido, para a realização de aprendizagens significativas, $o$ aluno era levado a construir, modificar, diversificar e coordenar seus esquemas, estabelecendo redes de significados que acabavam por enriquecer seu conhecimento do mundo físico e social, potencializando seu crescimento pessoal. Os conteúdos e atividades desenvolvidos foram organizados integrando as áreas de conhecimento. Por exemplo, o estudo do meio no Instituto Butantã possibilitou que as crianças ob-

\section{A AUTORA \\ Maria Júlia Rangel De Bonis \\ Professora de Português da Escola de Aplicação da Faculdade de Educação da Universidade de São Paulo.}


servassem os répteis, fizessem seus registros em bloquinhos (para posterior estudo do que foi visto no passeio, em sala de aula) e, na volta da visita, recolhessem sementes da árvore Jacarandá Mimoso, encontradas, dentro de seus frutos, pelo chão. Na classe, separaram as boas sementes para plantar. De posse das sementes, as crianças escreveram para os colegas das outras classes (num total de 140 crianças) uma pequena frase que lembrava a necessidade de fazer um jardim, assim como Monet havia feito, colocaram as sementes em saquinhos, anexaram aos desenhos feitos após o passeio e distribuíram aos colegas, numa pequena cerimônia na sala de aula, onde cantaram a música do cantor Toquinho chamada Imaginem, que fala da preservação da Natureza. Nesta atividade, trabalharam-se as áreas de Ciências, Português e Matemática.

As práticas de ensino adotadas tinham como ponto de partida e chegada o uso da linguagem. A prioridade estava no significado a precisão do texto redigido surgia do próprio interesse da criança em escrevê-lo de forma clara e para isto era necessário revisá-lo, colocando-se no lugar do leitor. Ana Maria Kaufman ${ }^{2}$ denominou a esta função reificação, a qual se dá quando o escritor toma distância do seu escrito e se coloca no lugar do leitor, organizando a forma e o conteúdo através da reescrita. Cada criança tinha o seu caderno, no qual eram registradas suas impressões, sempre depois de uma visita ou de outro acontecimento em sala de aula. Após ser escrito, o texto entrava num processo de revisão feito pelo próprio autor e pela professora. Esta indicava os erros, de preferência junto com o autor, para uma troca de idéias e para a correção ortográfica. Em diversas ocasiões, os próprios colegas trocavam os textos entre si para serem lidos e discutidos. Uma vez comentados e corrigidos, alguns eram passados a limpo, outros não. O passar a limpo era uma atividade extremamente rica, registrava-se a trajetória da criança no aperfeiçoamento de sua produção escrita, mas não era sempre que a criança estava disposta a reescrever sua história e isto deveria ser respeitado, pois, ao produzir o seu texto, muitos desenham para expressar os sentimentos e idéias.

Promover o descobrimento da utilidade da língua escrita como meio de comunicação e como fonte de informação, e também com o prazer de inventar, de construir um texto e de encontrar o tipo de escrita adequado à situação, propiciando o conhecimento das diferentes produções escritas. Foram conquistas que as crianças fizeram à medida que escreviam os seus textos, liam para os colegas ou mandavam para outros leitores fora da sala de aula. 


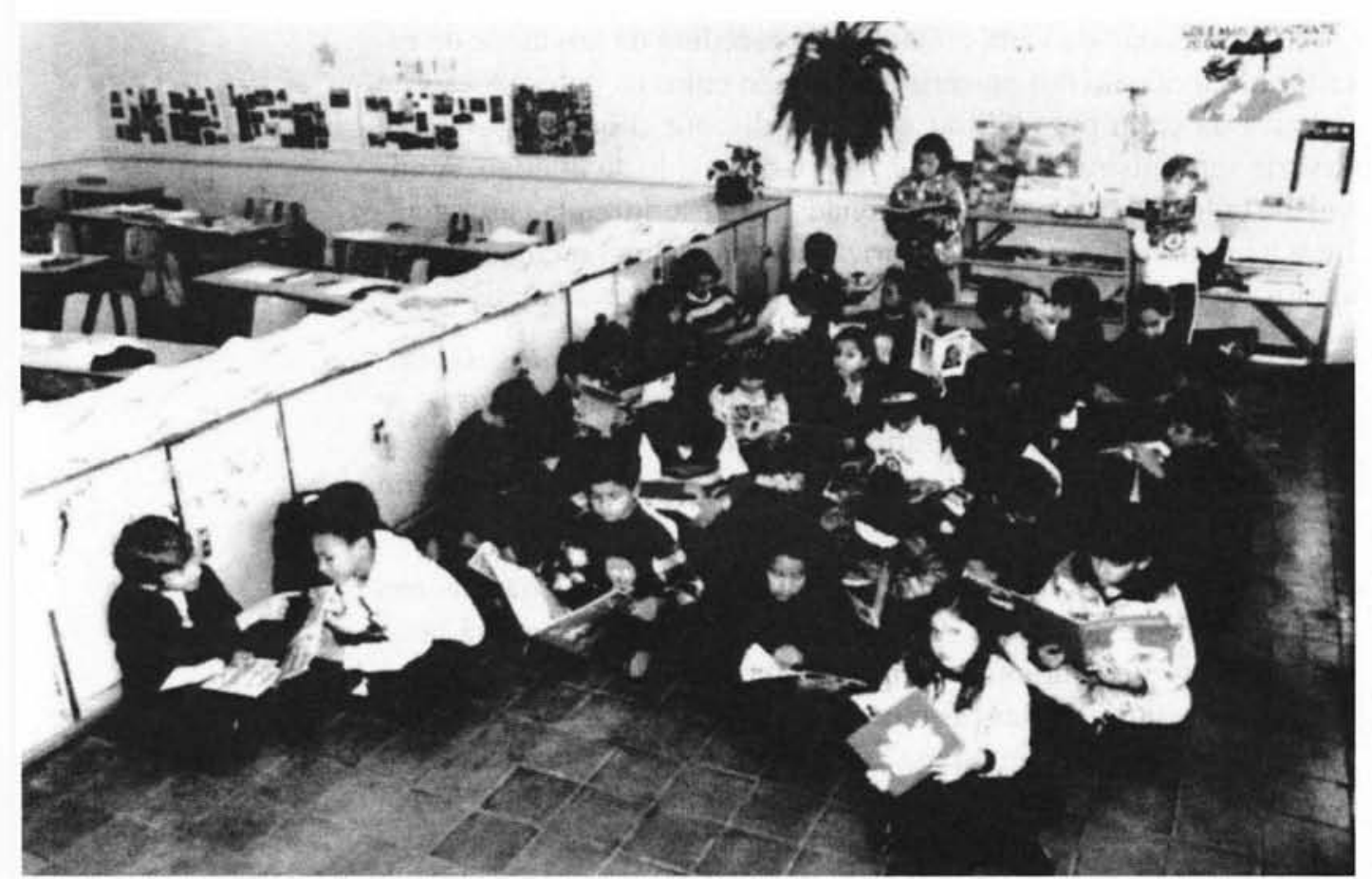

Página do livro Vivências pedagógicas. As crianças na sala de aula: espaço para leituras.

\section{CAPACIDADE COMUNICATIVA}

A prática do texto-livre em sala de aula, a partir das saídas ou de outros momentos significativos para as crianças, permitiu que a estrutura da língua escrita fosse sendo descoberta por elas. A meta do Projeto Vivência pedagógica foi a de conseguir que as crianças, baseadas em seus conhecimentos intuitivos da língua, desenvolvessem e aprimorassem a capacidade comunicativa, sabendo sempre que os seus textos teriam uma audiência, ou seja, mais de um leitor; diferentemente de uma visão behaviorista onde apenas a professora é a leitora dos textos produzidos pelos seus alunos. Um dos textos produzidos pelas crianças, no decorrer do ano, foi a escrita de uma carta para as crianças brasileiras que viviam em Boston, EUA. Todo o processo de escrita seguiu etapas que foram desde o estudo de como era a cidade de Boston, sua localização, até a criação de narrativas de como elas imaginavam aquela cidade. Uma estratégia utilizada foi a de levar muitas fotografias da cidade, dos seus parques, do rio que percorre a cidade.

Nestas escritas a magia estava presente, $o$ fantástico mesclava-se com a realidade e histórias de aventuras, poemas iam surgindo timidamente nos textos das crianças. 
A produção da carta coletiva foi precedida da atividade de escritura individual com posterior discussão entre os pares. A escrita coletiva da carta possibilitou ao grupo discutir o que de principal deveria ser registrado, ampliando a possibilidade de diálogo. A atividade coletiva, como a proporcionada pela escritura da carta, facilitou a aprendizagem e a exteriorização do discurso mediado pelos signos escritos. Para exemplificar, um trecho da carta coletiva:

... Conhecemos a cidade de Boston através de fotos. Gostamos do rio Charles porque ele é limpo, suas águas são azuis e se pode nadar nele no verão e patinar no inverno.

A ponte de pedra que tem sobre o rio, os cisnes e a vegetação ao redor do rio dão uma linda paisagem!

Para Celestin Freinet ${ }^{3}$, a participação ativa das crianças nas produções de textos é um dos elementos chave para motivá-las à produção escrita. Durante a escrita do livro Vivência pedagógica, a cooperação entre as crianças mereceu destaque. Sabíamos que sem a riqueza das relações interpessoais não seria possível trabalhar coletivamente. Na medida em que o trabalho era organizado de forma coletiva e cooperativa e que correspondia aos interesses e necessidades vitais da criança, modificava-se a própria concepção de disciplina, que passava a ser entendida como disciplina de trabalho.

Há duas histórias que as crianças escreveram que retratam perfeitamente a integração com que trabalhavam. Mais à frente, vamos destacar a importância do papel do professor, mas estas duas histórias nasceram de dois grupos e a professora só tomou conhecimento quando os grupos mostraram o resultado. A autonomia no trabalho foi um dos objetivos almejados.

Uma aventura

Eu, o Marcos e o Thiago Sousa estávamos no rio Charles, num barco passeando. De repente, um enorme monstro ataca o nosso pequeno barco e somos jogados na água. Ao cair na água, mergulho para escapar do monstro e vejo no fundo do rio um medalhão de ouro. Pego o medalhão, coloco no pescoço, volto para salvar meus amigos que estavam quase se afogando. Hoje, sou considerado um herói pois salvei a vida deles e também um milionário, pois vendi o medalhão e ganhei muito dinheiro.

\section{Rodrigo de Campos Pereira da Silva}


Eu e o Giliemerson viajamos a Boston para nos divertirmos um pouco e passear de avião. Enquanto isso no Brasil... Thiago Sousa, Marcos e Rodrigo Silva ficaram em casa com catapora e medo de altura.

\section{Leandro Armani Antonio}

O epistemólogo Jean Piaget ${ }^{4}$ destacou em seus escritos que o sujeito constrói o conhecimento através de sua interação com os objetos e que esta interação supõe que o mesmo levante hipóteses sobre os objetos e fenômenos com os quais interatua. Quando testa suas hipóteses, o papel do erro deve ser encarado não como um fracasso, mas como a possibilidade de novas indagações. Assim o papel do professor, neste trabalho, foi o de criar situações de aprendizagem que respondessem às necessidades do grupo, às hipóteses e às estratégias postas em ação pelas crianças; devendo avaliar o progresso do grupo e reavaliar constantemente seu trabalho.

Concluindo, Vivência pedagógica priorizou situações de interação entre os pares, que funcionavam como sócios na geração de idéias ou como possível audiência nos momentos da revisão dos escritos.

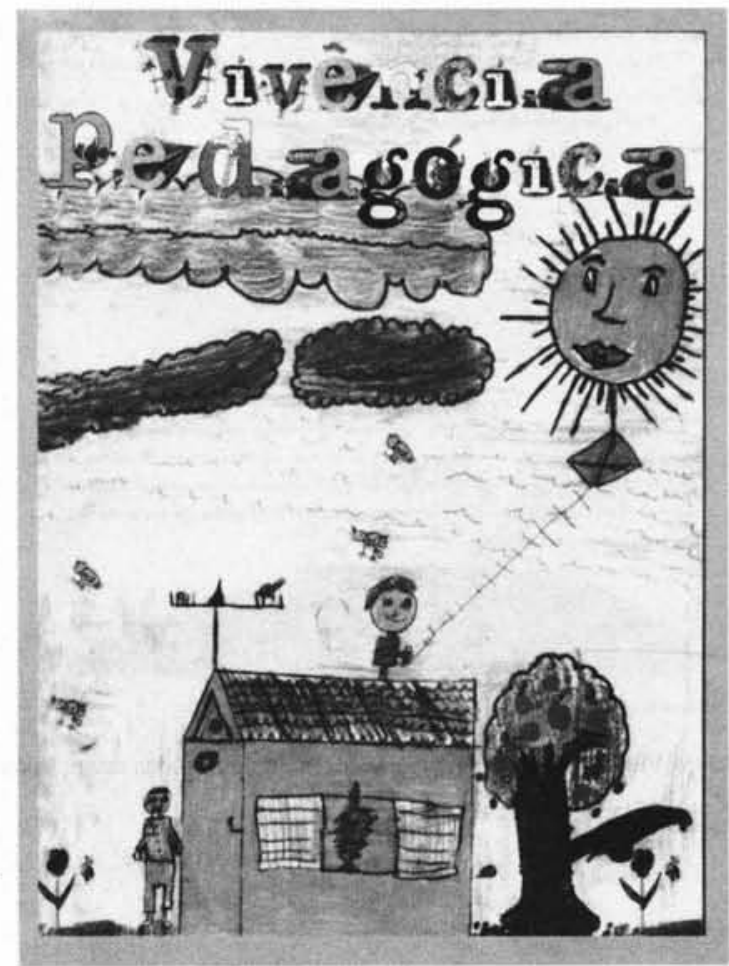

Capa do livro Vivências pedagógicas.

Essa experiência permitiu à professora afastar-se da postura de condutismo e trabalhar construtivamente, criando situações de contato, exploração e reflexão nas produções de textos, permitindo ao aluno otimizar seu aprendizado e aproveitar ao máximo suas possibilidades de escritor.

Ao término do projeto, organizou-se a edição de um livro com a coletânea de textos dos alunos. O livro Vivência pedagógica, publicado pela Coordenadoria de Comunicação Social da USP, concretiza a proposta inicial de fazer as crianças escreverem para serem lidas por outros. 


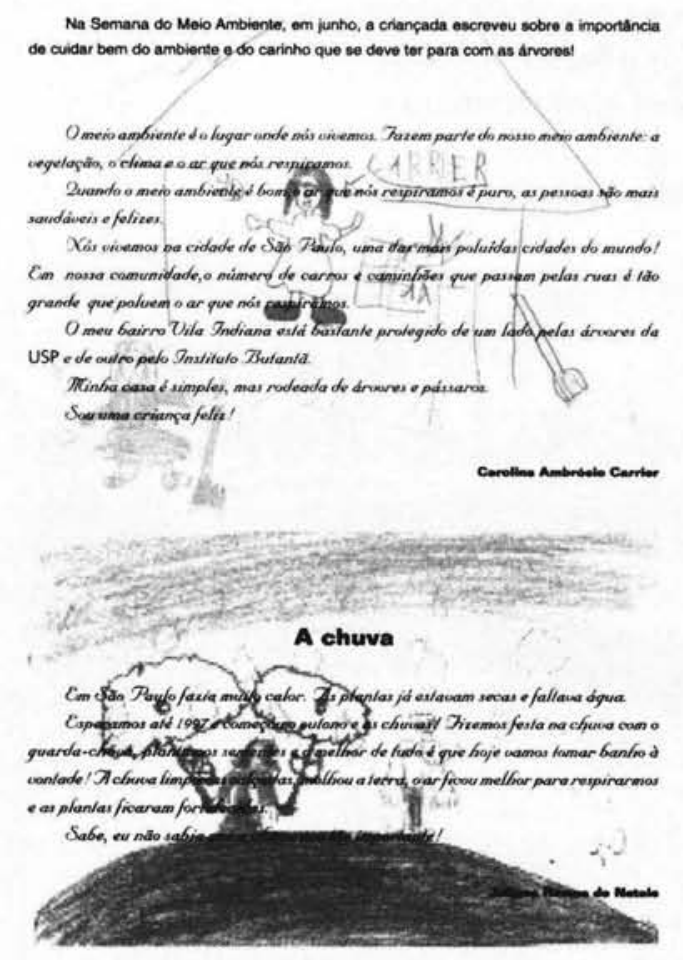

12 - Vnencia Pedagogica

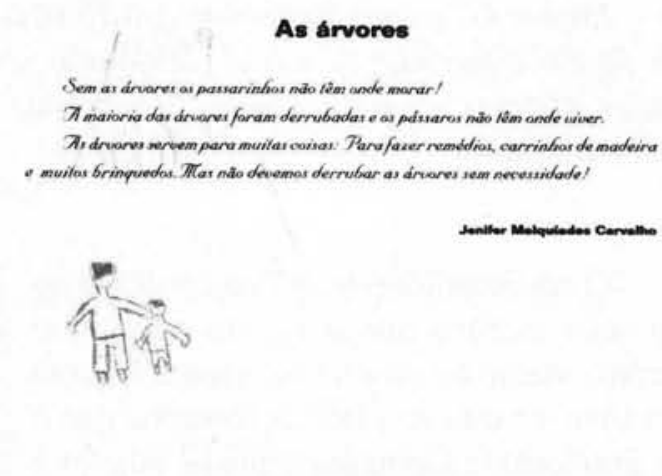

História de um menino

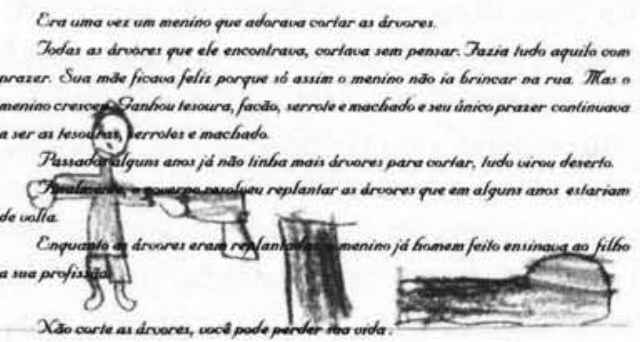

Nileso Nabolo Contriat

Livro Vivências pedagógicas mostra preocupação das crianças com o meio ambiente.

Resumo: Vivência Pedagógica foi um trabalho elaborado a partir das produçōes escritas de crianças da segunda série do ensino fundamental. As atividades foram realizadas em momentos posteriores aos estudos do meio e também fruto de outras situaçōes significativas que aconteceram em sala de aula. Considerando a escrita na sua função social, práticas pedagógicas foram planejadas, dando a oportunidade de as crianças produzirem textos bem adaptados a situaçōes reais, em atitudes cooperativas de troca de idéias e que ao final foram publicados em livro pela Coordenadoria de Comunicação Social da USP.

Palavras-chave: Vivência Pedagógica, produção de texto, ensino fundamental, ensino de Português
Abstract: Vivência Pedagógica, or "Pedagogical Experience", was a project put together after second grade children's written production. The activities were carried out after the medium was studied, and it was also a fruit of other meaningful situations that took place in the classroom. Considering writing in its social function, pedagogical practices were planned in a manner that gave the children the opportunity to produce texts that were well adapted to real situations via idea exchange cooperative attitudes. The USP Social Communication Coordinators published the texts in a book.

Key words: Vivência Pedagógica, text production, fundamental teaching, teaching of Portuguese 